\title{
Sabit Protetik Restorasyonlarda Marjinal Adaptasyon
}

\author{
Marginal Adaptation in Fixed Prosthetic Restorations \\ Muhammed Abdullah KELEŞ ${ }^{1}$, , Can $_{\text {METINNER }}^{2}$, Şebnem Begüm TÜRKER $^{3} \oplus$
}

Öz

Restorasyonların marjinal uyumu yetersiz olduğu durumlarda, zaman içerisinde yapıştırıcı simanın çözünmesi ile diş ve restorasyon arasında oluşacak olan boşluğu bakteri ve yiyecek artıkları doldurur. Bu durum plak birikimi ile sonuçlanır. Bu aralık alanda toplanan plak zaman içerisinde çürüklere, periodontal dokularda hasara ve sonuç olarak protezin başarısızlığına neden olmaktadır. Bu çalışmanın amacı marjinal adaptasyonu etkileyen faktörleri tartışmak ve diş yapısı ile restoratif materyal arasındaki marjinal adaptasyonu inceleme yöntemleri hakkında bilgi vermektir.

Anahtar Kelimeler: marjinal adaptasyon, mikrosızıntı

\section{Abstract}

Marginal fit plays an important role for a dental restoration. The degradation of cement in oral cavity can result in loss of marginal seal, retention of plague, development of secondary dental caries and periodontal diseases. Increasing marginal discrepancy results in progressive cement dissolution. The aim of this study was to discuss the factors effecting the marginal adaptation and informing about the methods which have been used to evaluate the marjinal adaptation between tooth structure and restorative materials.

Keywords: marginal adaptation, microleakage

Muhammed Abdullah Keleş

${ }^{l}$ Dr. Dt, Mihrimah Sultan Tip Merkezi, İstanbul, Türkiye

Can Metiner

${ }^{2}$ Araştırma Görevlisi Dt, Marmara Üniversitesi Diş Hekimliği Fakültesi, Protetik Diş Tedavisi Anablim Dalı İstanbul, Türkiye

Ş. Begüm Türker (四)

${ }^{3}$ Prof Dr. Marmara Üniversitesi Diş Hekimliği Fakültesi, Protetik Diş Tedavisi Anablim Dalı İstanbul, Türkiye

Marmara Üniversitesi Diş Hekimliği Fakültesi 34854 Başıbüyük, Maltepe / Istanbul, Türkiye

e-mail: begumturker@hotmail.com

Tel:0216.412.1621 (1777),Fax:02164210291

Submitted / Gönderilme: 10.04 .2019

Accepted/Kabul: 25.06 .2019

\section{GíRiş}

Sabit dental restorasyonlar temel olarak hastanın ağız ve genel sağlı̆̆ına zarar vermeden eksik dokuların estetiğini ve fonksiyonunu geri kazandırmayı amaçlar (Rosenstiel ve ark, 2006). Restorasyon ve preparasyon kenarları arasındaki morfolojik uyum marjinal adaptasyon olarak tanımlanır. Kuron restorasyonlarını prognozunda kullanılan materyalin kırılma direnci ve marjinal adaptasyonun başarı önemli kriterlerdir (Goldin ve ark, 2005).

Yetersiz marjinal adaptasyon destek diş ve çevre dokular üzerinde olumsuz etkiler oluşturabilmektedir. Marjinal aralık ağızdaki bakterilere geçiş yolu sağlar ve bu bakterilerin konağa adezyonuna zemin hazırlar. Bu durum sekonder çürük oluşumuna ve diş eti reaksiyonlarına zemin hazırlamaktadır. Bakterilerin dentin tübüllerinden pulpaya doğru penetrasyonu sonrasi endodontik inflamasyon meydana gelebilir. Yetersiz marjinal adaptasyona bağlı olarak diş üzerinde oluşan stresler dişin ve restorasyonun uzun dönemdeki başırısını olumsuz etkileyebilmektedir. (Nawafleh ve ark, 2013).

Restorasyonların kalitesi ve klinik başarısı değerlendirilirken marjinal adaptasyon temel belirleyici kriterdir. Tam seramik restorasyonlarda iyi bir marjinal adaptasyonun; restorasyonun uzun süreli klinik başarısı, dental ve periodontal dokuların bütünlüğü, yapıştırıcı simanının ömrü ve restorasyonun kırılma direnci için önemli kriterlerdir (Conrad ve ark, 2007).

Marjinal açıklık restorasyonun değiştirilmesi için tek başına yeterli değildir. Marjinal kenarlardaki aralığa bağlı olarak oluşacak mikrosızıntı ve sekonder çürüklerin varlı̆g1 restorasyonun prognozunu olumsuz etkilemektedir (Anusavice 1989). Restorasyon ile diş dokusu arasında sıvı, bakteri, molekül ve iyon geçişi mikrosızıntı olarak 
tanımlanabilir. Kuron marjininde var olan mikrosızıntı restorasyonun başarısızlığına sebep olabilir. Marjinal uyumsuzluk, siman kalınlığı ve mikrosızıntı arasında bir doğru orantı söz konusudur. Mikrosızıntının olması pulpa dokusunda hassasiyet oluşmasına ve zaman içerisinde dişin vitalitesinin kaybına neden olabilir (Bindl ve ark, 1989).

Kuron veya köprü restorasyonlarından sonra oluşan periodontal doku cevabını inceleyen bir çalışmada, pürüzlü yüzeye sahip, dişeti altında bitirilen ve marjinal adaptasyonu kötü olan restorasyonların çok daha yüksek oranda enflamasyona neden olduğunu ancak pürüzsüz cilalı yüzeylere sahip, marjinal adaptasyonu iyi restorasyonların çevresinde de diş eti enflamasyonunun gelişebildiği bildirilmiştir(Knoernschild ve Campbell 2000).

Literatürde sabit restorasyonların kabul edilebilir marjinal aralık değeri net olarak ifade edilmemektedir. Amerikan Diş Hekimleri Birliğinin (ADA) 8 nolu tanımlamasında dental kronun için yapıştırıcı simanının kalınlığının en az $40 \mu \mathrm{m}$ olması gerektiği bildirilmiştir (American Dental Association 1971). Klinik olarak bu değerlere nadiren ulaşılabilmesine rağmen, hedef değerler olarak kabul edilmektedir. McLean ve Von Fraunhofer, 5 yıllık periyotta 1000 sabit restorasyonun marjinal uyumunu incelemişler ve $80 \mu \mathrm{m}$ 'den az olan marjinal boşluğun klinik şartlar altında tespitinin zor olduğunu belirtmişlerdir (McLean ve von Fraunhofer 1971). Literatürde, tam seramik sistemler için farklı marjinal adaptasyon değerine bildiren çalışmalar mevcut iken optimum bir değer bildirilmemiştir. Marjinal adaptasyon çalışmalarında $7.5 \mu \mathrm{m}$ ile $206.3 \mu \mathrm{m}$ arası değişen oldukça farklı değerler ortaya görülmüştür. $\mathrm{Bu}$ çeşitliliğin nedeni uyumun değerlendirilmesinde kullanılan tekniklere, takip edilen test parametrelerine ve kullanılan materyale dayandırılabilir (Nawafleh ve ark, 2013).

Restorasyon materyali ile diş dokusu arasındaki geçiş morfolojik olarak farklı şekillerde belirlenebilir. Düzgün geçiş, iki materyal arasında aralık olmayan durumu; marjinal açıklık, iki materyal arasında temas olmayan durumu; pozitif basamak, restorasyon materyalinin seviyesinin diş dokusu seviyesinden dişarda olduğu durumu; negatif basamak, restorasyon materyalinin diş dokusu seviyesinden içerde olduğu durumu; overfilled ilişki, restorasyon materyalinin kavite marjini üzerine yayıldığı durumu ifade etmektedir (Anusavice 1989).

Kenar uyumunu inceleyen çalışmalarda ölçüm için kullanılan referans noktaları ve kullanılan terimler araştırmacılararasında farklılıkgöstermektedir.Bufarklılıkları önlemek için Holmes ve arkadaşları, çalışmalarında restorasyon ve diş dokusu arasındaki çok sayıda noktayı incelemiş ve kullanılan terimleri açıklamışlardır (Holmes ve ark, 1989). Restorasyon ile diş arasındaki uyumsuzluklar; iç yüzeyde, kenarlarda veya restorasyonun dış yüzeyinde yapılan ölçümlerle belirlenebilir. Restorasyonun iç yüzeyi ile preparasyonun aksiyal duvarı arasındaki dik ölçüm "internal aralık" olarak belirlenmektedir. Aynı ölçüm restorasyon kenarında yapıldı̆̆ı zaman "marjinal aralık" olarak ifade edilmektedir. Restorasyonun çıkış yönüne paralel olarak "vertikal marjinal uyumsuzluk", dikey olarak ise "horizontal marjinal uyumsuzluk" ölçülür. Horizontal ve vertikal marjinal uyumsuzluğun açısal kombinasyonu ise "mutlak marjinal uyumsuzluk" olarak tanımlanmıştır (Conrad ve ark, 2007; Holmes ve ark, 1989). Taşkın kenarlar, marjinal aralıktan restorasyonun dış yüzüne kadar olan mesafe ile eksik kenarlar (underextended), marjinal aralıktan dişin kenar açısına kadar olan mesafe ile ölçülür (Conrad ve ark, 2007; Holmes ve ark, 1989).

\section{Marjinal Adaptasyonu Etkileyen Faktörler}

Araştırmacılar farklı deney şartları kullanmışlar ve marjinal aralığ farklı şartlar altında ölçmüşlerdir. Ölçümü; in vivo veya in vitro, simantasyon öncesi veya sonras1, chamfer veya shoulder preparasyon dizaynı ve örnek sayısı ile örnek başına yapılan ölçüm sayısı etkilemektedir. Bu şartların hazırlanmasındaki farklılıklar sonuçlarda tutarsızlık olmasına yol açmaktadır ve seramik sistemlerin klinik olarak kabul edilebilir marjinal aralık değerinin tartışmalı olmasına neden olmaktadır. Aynı kuron sistemi bir çalışmada mükemmel marjinal uyuma sahip olarak düşünülürken başka bir çalışmada klinik olarak kabul edilebilir sınırlar içerisinde olmayabilmektedir (Nawafleh ve ark, 2013).

Klinik olarak, diş preparasyonu, ölçü tekniği ve simantasyon metodolojisi test sürecini komplike hale getirmekte, ideal şartlardan sapmalara neden olmakta ve in vivo çalışmaları in vitro çalışmalardan zor hale getirmektedir. İn vitro çalışmalar, in vivo olarak sağlanması çok zor olan optimal ve standardize şartları deneysel olarak sağlayabilmektedir (Nawafleh ve ark, 2013). Restorasyonların marjinal adaptasyonunu; kullanılan materyaller, preparasyon şekli ve tipi, kullanılan ölçü materyalleri ve yöntemleri, laboratuar işlemleri, kullanılan simanın viskozitesi, siman ile diş dokusu ile koping arasındaki fiziko-kimyasal bağlantı, nem, 1sı, kuron ve siman tipi ile simantasyon sırasında uygulanan yük gibi çok sayıda etkileyici faktör bulunmaktadır(Gavelis ve ark, 1981). 


\section{Preparasyonun şekli}

Preparasyon şeklinin olası etkisi simantasyon esnasında meydana gelmektedir. Prepare edilen dişin aksiyal duvarı ile kuronun iç yüzeyinin aksiyal duvarı birbirine temas ettiğinde siman materyali için gerekli kaçış yolu azalmaktadır. Kuron restorasyonu içindeki hidrostatik basınç artmaya başlar. Hastanın 1sırma kuvveti ile dengeleninceye kadar ve kuronun net oturmasını engelleyecek bir güç oluşturur. Siman tamamen sertleşmediyse uzaklaşmaya devam edecektir ancak sertleşmeye başladıysa aksiyal duvardaki siman partikülleri kuronun tam oturmasina engel olacaktır. Net bitim sınırlarının (shoulder gibi) fazla simanın simantasyon safhasının başlangıcında uzaklaşmasını kolaylaştırdığı ve böylece kuron restorasyonun tam oturmasına katkıda bulunduğu bildirilmiştir (Nawafleh ve ark, 2013).

Preparasyonun bitiş çizgisi restorasyon marjininde materyalin şeklini ve kalınlığını belirlediği gibi restorasyonun kenar uyumunu ve oturma açısını da etkiler. İyi uyumlu restorasyonlarda bile restorasyon ve preparasyon arasında bir aralık vardır. Bu aralığı azaltmak amacı ile bevel hazırlanması söz konusu olmuştur. Marjin açısının küçülmesi dar açı haline gelmesi ile restorasyon ile preparasyon arası mesafe azalır. Shillingburg ve ark. (1997) shoulder dizaynındaki metal kütlesinin daha fazla ve rijit olduğunu bildirmiştir. Böylece chamfer preparasyon şeklinden daha az distorsiyon gösterir (Schillinburg ve ark, 1997). Bu 2 preparasyon şeklindeki metal hacmi fark1 marjinaldeki distorsiyon miktarında farklılık göstermeyecek kadar azdır (Dittmer ve ark, 2009).

Goodacre ve arkadaşları 2001 yılında yaptıkları araştırmada son 50 yılda İngilizce yazılmış tüm literatürleri tarayarak hazırladıkları çalışmalarında kuronlar için preparasyon yöntemlerini incelemiş̧lerdir (Goodacre ve ark, 2001). Çalışmalarının sonucunda yaklaşım açısının 1020 derece arasında olması gerektiğini, kesici ve premolar dişler için minimum yüksekliğinin $3 \mathrm{~mm}$, molar dişler için $4 \mathrm{~mm}$ olması gerektiğini, tüm dişler için okluzoservikal/ insizoservikal yüksekliğin bukkolingual genişliğe oranının en az 0,4 olması gerektiğini, tutuculuk ve direnç sağlanması amac1 ile kısa okluzoservikal mesafeye sahip molar dişlerin çoğunda çentikler veya kutucuklar hazırlanması gerektiğini, estetik olumsuz etkilenmediği sürece supragingival basamaklar hazırlanması gerektiğini ve tam seramik restorasyonlar için shoulder veya chamfer preparasyonlar hazırlanabileceğini tespit etmişlerdir (Goodacre ve ark, 2001).

\section{Ölçü materyalleri ve ölçü yöntemleri}

Ölçü alımı esnasında gösterilen hassasiyet ve kullanılan ölçü materyali restorasyonun marjinal adaptasyonunu etkileyen faktörlerdir. Hassas tekniklerle alınmayan veya düşük boyutsal stabiliteli ölçü materyalleri kullanılarak alınan ölçülerden elde edilen model ile ağız içerisindeki preparasyon arasında farklılıklar oluşur. Oluşan bu farklılıklar elde edilecek restorasyonda marjinal uyumsuzluklara neden olur (McCabe ve ark, 1998). Bundan dolayı model elde etmek amaciyla yüksek boyutsal stabiliteye sahip ilave tipi silikon ölçü materyali kullanılması tavsiye edilir (Dietschi ve ark, 1997).

\section{Laboratuar işlemleri}

Modelleme, döküm, modelaj ve seramiğin işlenmesi gibi laboratuvar işlemleri marjinal adaptasyonu etkileyen bir diğer önemli faktördür. Bu işlemlerde gösterilen hassasiyet restorasyonun başarısı ile doğru orantılıdır. Venerleme işlemindeki sıcaklığın metal veya seramik kor materyallerinin marjinal uyumunu etkilediği bilinmektedir. İlk fırınlama aşamasında marjinal uyum değeri büyük miktarda değişmektedir, venerleme işleminin özellikle horizontal düzlemdeki adaptasyona büyük etkisi vardır. Bu distorsiyon protezin okluzalde yer değiştirmesine neden olabilir ve tam seramik restorasyonların yük taşıma kapasitesinde düşüşe neden olabilir. Metal-seramik restorasyonlarda marjinaldeki preparasyon şekli firınlama esnasındaki marjinal distorsiyonu etkilemektedir (Nawafleh ve ark, 2013).

\section{Kullanılan siman tipleri ve simantasyon}

Simante edilmiş ve simante edilmemiş kuronların marjinal aralık değerlerinin ölçümü sonuçları etkilemektedir. Marjinal uyumsuzluk simantasyon sonrası genelde artmaktadır, simantasyon işlemi sonucunda kuronun marjinal adaptasyonunda kesintiler meydana gelebilir ve simantasyon yetersiz marjinal kapama ile sonlanabilir (Gavelis ve ark, 2004). Çoğu araştırmacı simantasyon sonrası simantasyon öncesine göre oldukça yüksek marjinal uyumsuzluklarla karşıllaştıklarını belirtmişlerdir (Nawafleh ve ark, 2013).

Kontrolsiz parmak basincı ve kuron restorasyonun iç kısmını simanla aşırı doldurma gibi sebepler simanın dengesiz akışına neden olup bir aksiyal duvarda siman film kalınlığının kalın olmasına karşı taraftaki aksiyal duvarda ise ince olmasina neden olabilir ve marjinal 
adaptasyonun olumsuz yönde etkileyebilir (Pilo ve Cardash 1998).

Kullanılan siman tipi de kuronların marjinal uyumunu etkileyebilmektedir. Marjinal adaptasyonda yapıştırma simanının viskozitesi, doldurucu partiküllerin boyutu ve oranı, polimerizasyon büzülmesi, çözünürlük katsayısı ve bağlantı kuvveti belirleyici etkenlerdendir. Simanın mekanik özellikleri ve aşınma direnci doldurucu içeriğine bağlıdır. Kompozit rezin simanların viskozitesi, doldurucu oranı düşürülerek, monomerin yapısını veya doldurucu tipini değiştirerek azaltılabilir (Haffernan ve ark, 2002).

Yıldız ve arkadaşları 2013 yılında yaptıkları in vitro çalışmada $\mathrm{CAD} / \mathrm{CAM}$ ile üretilen zirkonya kuronları farklı yapıştırma ajanları ile yapıştırmışlar ve marjinal ve internal adaptasyonlarını değerlendirmişlerdir (Yildiz ve ark, 2013). Çalışmada Lava zirkonyum oksit bloklar ve IPS ZirCAD zirkonyum oksit bloklar kullanılmıştır. Simantasyonda kullanılan yapıştırma ajanları ise Variolink II ve Multilink Automix'dir. İnternal ve marjinal adaptasyon değerlendirilmesi için silikon replika tekniği kullanılmıştır. Marjinal aralık değerleri Lava kuronlar için $89.26 \mu \mathrm{m}$, IPS ZirCad kuronlar için ise $88.84 \mu \mathrm{m}$ olarak ölçülmüştür. Lava kuronlar, IPS ZirCad kuronlara göre çok daha yüksek aksiyal ve okluzal aralık değerleri göstermiştir. Fakat her 2 sistemin marjinal uyum değerleri kabul edilebilir sınırlar içerisindedir (Yildiz ve ark, 2013).

\section{Marjinal Adaptasyon İnceleme Yöntemleri}

Protetik restorasyonların marjinal uyumları farklı yöntemlerle incelenebilir. $\mathrm{Bu}$ yöntemler aşağıda gösterilmiştir (Şekil 1.). Marjinal uyumun incelenmesinde en siklıkla morfolojik kriterleri esas olan yöntemler tercih edilmektedir. Bu yöntemler içerisinde de en çok direkt teknikle ölçüm metodu (\%47.5) tercih edilmektedir (Nawafleh ve ark., 2013). Bu yöntemde diş veya siman aralığını taklit eden bir replika olmadığı için diğer tekniklere göre daha ucuzdur ve zaman kaybı yaşanmaz. Replika oluşturulmasına bağlı hatalar da görülmemektedir. Ancak bu yöntem sadece in vitro araştırmalar için uygulanabilmektedir.

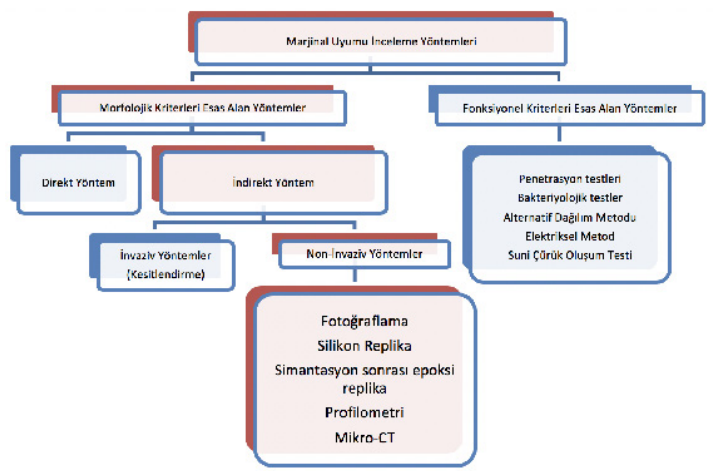

Şekil 1. Marjinal uyumu inceleme yöntemleri

\section{Morfolojik Kriterleri Esas Alan Yöntemler}

Morfolojik kriterleri esas alan yöntemler direkt ve indirekt yöntemler olmak üzere iki başlık altında incelenir.

\section{Direkt Yöntem}

Restorasyonun uygulandığı dişin direkt olarak kendisinin incelendiği bu yöntemde morfolojik özellikleri değerlendirmek amaçlanır. İn vivo çalışmalarda marjinal adaptasyon değerlendirmeleri sıklıkla USPHS veya FDI kritleri kullanılarak gözlemsel olarak yapılabilmektedir. Hastalarda yapılan bu değerlendirmelerin tekrarlanması güçtür ve dolayısı ile standardizasyonu sağlanamamaktadır. Ayrıca direkt yapılacak incelemelerde referans noktalarının standardizasyonu zordur ve görüntülemeye bağl1 hatalar da oluşabilmektedir (Contrepois ve ark., 2013; Roulet ve Herder 1991). Direkt yöntemin dezavantajlarından birisi de değerlendirme sırasında hastaya ihtiyaç duyulmasıdır. Direkt olarak hastada inceleme yapıldığından restorasyonun herhangi bir kaydı bulunmaz dolayısıyla da tekrar değerlendirme yapmak imkansızdır (Anusavice 1989). İndirekt değerlendirmelerde amaç verilerin depolanması ve uzun dönem sonuçlarının kıyaslanmasıdır. Bu yöntem ile restorasyonları değerlendirirken diş ile restorasyon yeterince kontrast yaratmadığından, göz marjinal uyumu yeterince iyi ayırt edemeyebilir. İndirekt metodlar direkt metodlardan daha sıklıkla kullanılmaktadır ( Anusavice 1989). 


\section{İndirekt Yöntemler}

İndirekt metodlar değerlendirme yapılabilmesi amacıyla mevcut klinik durumun tekrar yapılandırılması için verilerin depolanması temeline dayanır. Bu değerlendirmeler, optik (standardize edilmiş fotoğraflar, halogramlar ve fotogremetri esasına dayanan dijital dökümanlar) veya mekanik (replikalar kullanılarak veya okluzal yüzeyin taranması ile elde edilen verilerle) yöntemlerle yapılabilir. İndirekt metodlar, her iki yöntemin kombinasyonu (replikalar ve fotograflar vb.) ile de kullanılabilirler (Anusavice 1989). İn vivo çalışmalarda standardizasyon in vitro çalışmalara göre daha zor olduğu için ölçüm sonuçları in vitro çalışmalardan daha farklı olabilmektedir. Ayrıca ölçüm yapmak için de in vitro çalışmalarda kullanılan teknikler kullanılamamaktadır.

Simantasyon sonrasında invaziv veya non invaziv yöntemler kullanılarak indirekt değerlendirmeler yapılabilmektedir. Non-invaziv metodlarda sıklıkla simante edilmiş restorasyonun bir kopyası oluşturulur ve bunun üzerinden değerlendirmeler yapılır. Amaç restorasyona ve diş dokusuna direkt olarak müdahale etmeden verilerin depolanmasıdır. İnvaziv metodlarda marjinal uyum çekilmiş dişlere yapılan restorasyonların kesitlendirilerek incelenmesi ile gerçekleştirilir. Nawafleh ve arkadaşlarının yaptığı çalışmada kesitlendirme tekniğinin marjinal uyum incelenme çalışmalarında \%23.5 oranında kullanıldığ görülmüştür (Nawafleh ve ark., 2013). Bu teknikle yapılan ölçümler kesitlendirme yüzeyiyle sınırlı kalmaktadır ve restorasyonun çevresel uyumunu temsil etmemektedir.

Fotoğraflama metodunun avantajları; marjinal adaptasyondaki küçük farklılıkların ayırt edilebilmesi, marjinal özelliklerin kompleks olduğu durumlarda mantıklı bir ortalama alınabilmesinin sağlanması, uzun dönem değişikliklerin tek seferde kerede gözlenebilmesi, ileride gerekli olabilecek incelemelere izin vermesi ve verilerin birçok araştırmacı tarafından değerlendirilmesine olanak vermesidir. Ancak bu yöntemin diş dokusu ile kontrast oluşturamayan materyallerde kullanılamaması dezavantajıdır (Anusavice 1989). Bu tür restorasyonlar için replika teknikleri ile marjinal adaptasyonların model üzerinde değerlendirilmesi seçeneği uygundur. Marjinal aralık simante edilmiş restorasyonlarda 1şık mikroskobu veya SEM (scanning electron microscopy) kullanılarak ölçülebilmektedir. Schmalz ve arkadaşlarının class II seramik inleylerin marjinal adaptasyonlarını incelediği çalışmasında SEM ile alınan görüntülerden yapılan ölçümlerin 1 şık mikroskobu kullanılarak alınan görüntülerden daha başarılı olduğunu göstermişlerdir (Schmalz ve ark., 1995). Klinik çalışmalardaki marjinal adaptasyon incelemelerinin sıklıkla scanning electron microscope (SEM) kullanılarak yapıldığı görülmüş ve SEM kullanılarak yapılan ölçümlerde kompleks marjin morfolojilerinin daha net bir şekilde takip edilebildiği bildirilmiştir (Roulet ve ark., 1989; Van Dijken ve Hörstedt, 1996; Gemalmaz ve ark., 2001; Göhring ve Roos, 2005; Guess ve ark., 2009; Emiroğlu ve ark., 2016). $\mathrm{Bu}$ amaçla klinik uygulama yapılmış olan dişten silikon bazlı ölçü maddeleri ile alınan ölçülere alçı ya da epoksi rezin dökülerek hazırlanan replikalar üzerinde inceleme yapılır. Bu incelemelerde sıklıkla kantitatif olarak devamlı marjin yüzdelerine ve kalitatif olarak da marjinal kenarların uyumuna bakılmıştır.

Marjinal adaptasyonun in vivo olarak değerlendirilmesi Modifiye Ryge/Modifiye USPHS veya FDI kriterleri ile gözlemsel olarak yapılabilmektedir. Bu kriterler ile skorlama yapılarak kantitatif değerlendirmeler yapmamıza imkan sağlayan çeşitli skalalar geliştirilmiştir.

Roulet ve arkadaşlarının 1989 yılında yaptıkları çalışmasında skorlama aşağıdaki gibi yapılmıştır (Roulet ve ark., 1989).

1. Devamlı marjin; iki yüzeyin birbirine temasta olduğu alanda herhangi bir düzensizlik yok ve bütünlük gözlenen yüzeyler

2. Marjinal aralık (gap); yüzeylerin birbiriyle temasta olduğu alanda küçük düzensizlikler gözlenen yüzeyler

3. Değerlendirilemeyen bölgeler; ilk iki madde ile skorlanamayan yüzeyler.

Van Dijken ve arkadaşlarının 1996 yılında yaptıkları çalışmasında ise skorlama biraz daha detaylı olacak şekilde yapılmıştır (Van Dijken ve Hörstedt, 1996).

1. Herhangi bir marjinal açıklık veya eksiklik yok

2. Hafif marjinal düzensizlikler var, aralık yok

3. Şiddetli marjinal düzensizlikler var, aralık yok

4. Aralık var, restorasyon marjininde sınırı gözlenebilen çatlak hattı mevcut

5. Şiddetli aralık var.

Marjinal adaptasyonun değerlendirilmesinde kullanılan diğer replika metodu ise simantasyon öncesi farklı viskozitede silikon bazlı ölçü materyalleri kullanılarak iç uyum replikalarının elde edilmesi ve bu replikaların kesitlendirilerek ışık mikroskobu altında değerlendirilmesi esasına dayanır (Anusavice 1989). Bu teknikte kuron düşük 
vizkoziteli light-body silikon materyali ile doldurulur ve simantasyon işleminde olduğu gibi die üzerine oturtulur. Silikon sertleştikten sonra, kuron hassas bir şekilde die üzerinden çıkarılır, kuron içerisindeki silikon çıkartılmadan heavy-body silikon enjekte edilir ve stabilize olması sağlanır. Bu aşamadan sonra light body silikon kesitlendirilerek farklı bölgelerden ölçüm yapılabilir (Nawafleh ve ark, 2013). Bazı araştırmacılar ölçü replika tekniğinde modifikasyona gitmişler ve kuronu die üzerine yerleştirdikten sonra marjinal aralığın eksternal ölçüsünü almışlardır. Daha sonra bu ölçü epoksi rezin materyali ile dökülmüştür. Ancak ölçü replika tekniğinin bazı sınırlamaları ve olası hataları olabilmektedir, kuron marjinlerini ve bitim çizgilerini saptamada zorluk yaşamak ve elastomerik film tabakasının kurondan çıkarma esnasında yırtılması ve deforme olmas1 gibi olasıl1klar mevcuttur (Wolfart ve ark, 2003). Kesitlendirme düzleminde yapılacak hatalar ise sonuçların tahminlerin çok üzerinde çıkmasına neden olabilmektedir (Coli ve Karlsson 2004).

Laurent ve arkadaşları, eğer doğru silikon kullanılırsa siman aralığının doğru bir şekilde replikası alınabileceğini ve siman kalınlığının ölçümünün doğru yapılabileceğini belirtmişlerdir (Laurent ve ark, 2008). Rahme ve arkadaşları ${ }^{25}$, Procera kuronların marjinal aralık ölçümünde silikon replika tekniği ve kesitlendirme tekniği arasında önemli fark bulamamışlardır ve replika tekniğinde düşük viskoziteli silikon kullanmanın cam iyonomer siman ile simante edilmiş krondaki siman kalınlığı kadar film kalınlığ 1 elde edileceğini savunmuşlardır (Nawafleh ve ark, 2013).

Profilometri non-invaziv bir metottur. Hem örneğin hem de güdüğün monitörde aynı odak düzlemi içerisinde görüntüsünü sunan bir yöntemdir (Balkaya ve ark, 2005). Ancak, profilometri ile marjinal bölgedeki siman tabakasının kalınlığı indirekt olarak saptanabilir ve takip eden analizlerde örnekleri konumlandırırken olağanüstü dikkatli olunmalıdır aksi halde ölçümlerde tutarsızlıklar ortaya çıkar (Good ve ark, 2009). Dijimatik mikrometre ve mikro BT tarama teknik zorluklarından dolayı çok tercih edilen yöntemler değillerdir (Nawafleh ve ark, 2013).

İnvaziv metodlar ise kesitlendirme yöntemine dayanır. Marjinal adaptasyonun in vitro olarak değerlendirilmesi için çekilmiş dişler üzerine standart koşullarda uygulanan restorasyonlar kullanılır. Bu dişlerden elde edilen kesitler 1şık mikroskobu altında incelenerek marjinal adaptasyon değerlendirilir (Thordrup ve ark, 1994). Kesitlendirme metodu, siman kalınlığının ve marjinal aralığın vertikal ve horizontal düzlemlerde direkt ölçümüne izin vermektedir, bilgisayara ve tekrar pozisyonlandırmaya bağlı hataları da minimale indirmektedir (Good ve ark, 2009). Aynı zamanda köprü restorasyonu örneklerinde konnektöre komşu bölgedeki marjinal aralığın kesintisiz görüntülenmesini sağlar (Kunii ve ark, 2007). Ancak bu metot, uzun dönem analizlere ve aynı örnekleri kullanarak üretimin farklı aşamalarından önce ve sonraki sonuçlar arasında karşılaştırma yapmaya izin vermez. Yapılan ölçümlerin sayısı kesitlendirilmiş düzlem sayısı ile sınırlıdır bu da tüm kuronun uyumunu sonuçlara yansıtmayabilir (Mitchell ve ark, 2001).

$\mathrm{Bu}$ metotlarla yapılan marjinal ölçümler aynı seramik sistem içinde dahi büyük farklılıklar göstermektedir. Örneğin In-Ceram Alumina kuronların marjinal aralık değerleri literatürde 7.5 ila $161 \mu \mathrm{m}$ arasında değişmektedir. $\mathrm{Bu}$ çalışmalarda kullanılan tekniklerin ve değişkenlerin çok farklı olması bu geniş sonuç aralığına neden olmuştur. Bu yüzden, restorasyonların gerçek uyumlarını yansıtmıyor olabilirler (Pera ve ark, 1994; Sulaiman ve ark, 1997). Benzer çalışmaların sonuçları karşılaştırıldığında, aynı teknik ve değişkenleri kullanan bu çalışmaların sonuçları sırasıyla $57 \mu \mathrm{m}$ ve $49.8 \mu \mathrm{m}$ 'dir. Her 2 çalışmada da profil projektörü kullanılmıştır. Örneklerin ölçüm sayısı hariç diğer değişkenler aynıdır bu da sonuçları kıyaslanabilir kılmaktadır (Balkaya ve ark, 2005; Sulaiman ve ark, 1997).

Bazı çalışmalarda silikon replika ve kesitlendirme metotları kombine edilerek kullanılmıştır. Bir çalışmada Cerec kuronların marjinal aralık değerleri ölçülmüştür. Silikon replika tekniği ve kesitlendirme tekniği kullanılmış ve sırasılya; chamfer preparasyonu için $94 \mu \mathrm{m}$ ve $91 \mu \mathrm{m}$, shoulder preparasyonu için ise $91 \mu \mathrm{m}$ ve $79 \mu \mathrm{m}$ marjinal aralık değerleri bulunmuştur(Tsitrou ve ark, 2007).

Shearer ve ark. In-Ceram sisteminin marjinal aralık değerlerini kesitlendirme yöntemi ve silikon replika yöntemini kullanarak sırasıyla $8.3 \mu \mathrm{m}$ ve $28.6 \mu \mathrm{m}$ değerlerini bulmuşlardır. Kesitlendirme tekniğinin silikon replika tekniğinden daha doğru sonuçlar verdiğini savunmaktadırlar (Shearer ve ark, 1996). Rahme ve arkadaşları ise yine ayn 2 tekniği Procera kopingler için kullanmışlar ve kesitlendirme ve silikon replika tekniği ile surasıyla $31.9 \mu \mathrm{m}$ ve $33.6 \mu \mathrm{m}$ değerlerini bulmuşlardır. 2 teknik arasında önemli fark rapor edilmemiştir (Rahme ve ark, 2008).

Borba ve arkadaşları (2011) micro-CT tekniğini kullanarak, 3 üyeli sabit köprü restorasyonlarının marjinal ve internal uyumunu ölçmüşlerdir. 3 üyeli köprülerin üretileceği prepare edilmiş dişleri taklit eden, paslanmaz çelik modeller hazırlanmıştır. 2 farklı seramik sistemik 
sistemi kullanılarak altyapılar üretilmiş ve önerilen porselen vener sistemi kullanılmıştır. Köprüler modellere yerleştirilmiş ve micro-CT ile taranmıştır. NRecon ve CTAn bilgisayar yazılımları ile bilgiler işlenmiş ve kesitleri incelemek için Adobe Photoshop ve Image J programları kullanılmıştır. 5 noktadan ölçüm yapılmıştır. Bu bölgeler; marjinal bölge, chamfer bölgesi, aksiyal duvar, aksiyookluzal geçiş alanı ve okluzal alandır. Horizontal marjinal uyumsuzluk ise başka fotoğraflar ile değerlendirilmiştir. 5 noktadaki ölçümlerde birbirinden farklı değerler çıkmıştır. Aksiyal duvar ve aksiyo-okluzal geçiş bölgesinde yapılan ölçümler hariç Vita In-Ceram Zirkonya değerleri Vita InCeram YZ değerlerinden daha büyük çıkmıştır. Okluzal ölçümlerde bulunan değerler ise her 2 sistem için de yüksek çıkmıştır. Marjinaldeki ve aksiyal duvardaki ölçümler ise en düşük çıkan ölçümler olmuştur (Borba ve ark, 2011).

Quante ve $\operatorname{arkadaşlar1}^{37}$ (2008) yapmış olduğu çalışmada ise "laser - melting" teknolojisi ile üretilen metal-seramik kronların internal ve marjinal uyumu in vivo olarak incelenmiştir. Wirobond $\mathrm{C}$ ve BioPontoStar metal alaşımları ile altyapıların hazırlandığı araştırmada marjinal aralık değerleri $74 \mu \mathrm{m}$ ile $99 \mu \mathrm{m}$ arasında bulunmuştur. Internal aralık değerleri ise $250 \mu \mathrm{m}$ ile $350 \mu \mathrm{m}$ arasında değişen değerlerde ölçülmüştür. $\mathrm{Bu}$ değerler "laser melting" teknolojisi ile üretilen metal-seramik kronların konvansiyonel üretim teknikleri ile kıyaslanabilir olduğunu göstermektedir(Quante ve ark, 2008).

Gassino ve arkadaşlarının ${ }^{38}$ yapmış olduğu bir çalışmada örnek başına 18 ölçümün deneysel kronlar için yeterli olduğu düşünülmüş, hastaya özel yapılan kronlarda ise 90 ölçümün yapılması uygun görülmüştür (Gassino ve ark, 2004). Gonzalo ve ark. yapmış oldukları çalışmada her bir örnek için vestibül ve oral yüzeylerden 30'ar ölçümü yeterli görmüşlerdir (Gonzalo ve ark, 2009). Yeo ve ark. yapmış oldukları in vitro marjinal uyum çalışmasında 50 noktadan ölçüm yapmışlardır(Yeo ve ark, 2003).

\section{Fonksiyonel Kriterleri Esas Alan Yöntemler}

Fonksiyonel kriterleri esas alarak marjinal sızıntıyı ölçen ve marjin kalitesinin değerlendirilmesini sağlayan testler; penetrasyon testleri, bakteriyolojik testler, alternatif dağılım metodu, elektriksel metod ve suni çürük oluşumu testidir (Anusavice 1989).

\section{Penetrasyon Testleri}

Boya penetrasyon testi yöntemi marjin uyumunu değerlendirmek amacı ile kullanılan en eski ve yaygın metoddur. Penetrasyon testlerinde diş yüzeyinde restorasyon haricindeki alanlar mum veya cila ile kaplanır, dişler boya içeren solüsyona batırılır ve sonrasında akrile gömülerek kesitlendirilir. Bu metodda sıklıkla kullanılan boya materyalleri metilen mavisi, anilin mavisi, bazik fuksin, elektrosin ve floresan boyalardir. Penetrasyon metodunda marjinal sizıntı, boya ile restorasyon materyali arasındaki yüzey etkileşimine, boyanın moleküler hacmine, moleküler kutuplaşmaya, zamana ve geçirgenliğe bağlıdır (Anusavice 1989). Heintze ${ }^{41}$ (2013) boya penetrasyonu ile yapılan mikrosızıntı testlerinin post-operatif hassasiyet, tutuculuk, marjinal renklenme gibi klinik parametrelerle ilişkilendirilemeyeceğini bildirmiştir. (Heintze 2013).

Bazı araştırmacılar, marjin penetrasyonu testleri için boyalar yerine ${ }^{131} \mathrm{I},{ }^{35} \mathrm{~S},{ }^{32} \mathrm{P}$ gibi radyoaktif iyonları tercih etmektedirler. Ancak radyoaktif iyonların kullanımının, özel ekipman ve radyoaktif madde kullanımı için özel izin gerektirme dezavantajının yanısıra yıkıcı materyaller olduklarından yorumlanabilmesi zordur, uzun dönem çalışmaları imkansızdır (Anusavice 1989).

Garcia ve arkadaşları $^{42}$ aynı siman ile yapıştırılan Lava ve Zirkon zahn kopinglerin marjinal adaptasyon ve mikrosızıntısnı karşılaştırmıştır. (Garcia ve ark, 2011). 20 adet çekilmiş maksiler premolar diş kullanılmış ve 2 gruba ayrılmıştır. 1. Gruptaki dişler Lava kopingler için prepare edilmiş, 2. gruptaki dişler ise Zirkon zahn kopingler için prepare edilmiştir. Dişler bu 2 sistemin standart prosedürüne göre prepare edilmiştir. Marjinal uyum 8 ayrı noktadan RelyX U100 ile simanı ile simante edilmeden önce ve sonra ölçülmüştür. Önce 1 sıl çevirim işlemine tabi tutulmuş sonra \%2'lik fuksin solusyonuna tabi tutulmuş ve bukkolingual olarak kesilerek hem vestibüler hem de palatinal bölgederde mikrosızıntısı ölçülmüştür. 2 sistem arasında marjinal uyum değerleri istatistiksel olarak önemli ölçüde farklılık göstermiştir. En iyi adaptasyon sonuçlarını Lava sergilemiştir, simantasyon öncesi 19.7 $\mu \mathrm{m}$ ve sonrasında $15 \mu \mathrm{m}$ değerleri ölçülmüştür. Zirkon zahn'da ölçülen değerler ise simantasyon öncesi $28.1 \mu \mathrm{m}$ simantasyon sonrası $22.8 \mu \mathrm{m}$ 'dir. Marjinal adaptasyonun aksine mikrosızıntı değerlerinde önemli farklılık yoktur. Lava $314.2 \mu \mathrm{m}$ ve Zirkon zahn $319.8 \mu \mathrm{m}$ ortalama değerler elde edilmiştir. Sonuç olarak Lava sistemi ile daha iyi marjinal adaptasyon değerleri kaydedilmiştir, mikrosızıntı 
açısından ise önemli bir fark olmadığını bildirmişlerdir (Garcia ve ark, 2011).

\section{Bakteriyolojik Testler}

Marjinal sızıntı ölçümünde bakteriyolojik testler kliniği en iyi taklit eden testlerdir. Bu yöntemde restorasyonlar, steril çekilmiş dişlere uygulanır ve pigment boyayan mikroorganizmaların bulunduğu bir süspansiyona batırılır. Restorasyon çıkartıldıktan sonra alınan örneklere kültür yapılır mikroorganizmalar belirlenir(Anusavice 1989).

\section{Alternatif Dağılım Metodu}

Alternatif dağ 1 lım metodu restorasyonun altına polietilenglikol "radiotracer"yerleştirilerek restorasyonların yapay tükrük içerisinde bekletilmesi ve daha sonra meydana gelen sızıntı miktarının monitörde incelenmesi yöntemidir (Anusavice 1989).

\section{Elektriksel Metot}

Elektriği iletmeyen restoratif materyallerin marjin kalitesinin incelenmesi ile sınırlı olan elektriksel metod yöntemi dişe zarar vermeden sızıntı bölgelerini seri olarak görüntülemeye olanak sağlayan bir yöntemdir (Anusavice 1989).

\section{Suni Çürük Oluşumu Testi}

Suni çürük oluşum testi $5-55{ }^{\circ} \mathrm{C}$ de 1 sıl çevrim işlemi uygulanan restorasyonların laktat jele batırılarak, başlangıç çürük lezyonlarına benzer yüzeysel demineralize mine alanlarının oluşturulması ve tespit edilmesi yöntemidir. Kimyasal model olmasının haricinde mikrobiyolojik aktiviteyi etkileyen parametreler (floridin mikrobiolojik inhibisyonu veya amalgamın korozyon ürünleri vb.) bu yöntemde göz ardı edilmektedir(Anusavice 1989).

\section{SONUÇ}

Literatürde sabit kuron ve köprü restorasyonların marjinal adaptasyonunu değerlendirmek için kullanılan test metotları üzerinde bir konsensus bulunmamaktadır. Test tekniklerinde ve deney koşullarındaki farklılıklar değişik sonuçların elde edilmesine neden olmaktadır. Direkt görüntüleme metodu en çok kullanılan metot olup, sonuçlar tekrarlanabilir niteliktedir. Değerlendirme için 2 farklı ölçüm metodunun kullanılmasının sonuçların güvenilirliğini arttırabileceği sonucuna varılmıştır.

\section{KAYNAKLAR}

1. American Dental Association. ANSI/ADA Specification No.8 for zinc phosphate cement. In: Guide to Dental Materials and Devices. $5^{\text {th }}$ ed, Chicago, 1971

2. Anusavice KJ. Quality Evaluation of Dental Restorations. Criteria of Placement and Replacement. Quintessence publishing Co. Inc., Chicago, 1989

3. Balkaya MC, Cinar A, Pamuk S. Influence of firing cycles on the margin distortionof 3 all-ceramic crown systems. J Prosthet Dent 2005; 93:346-55

4. Bindl A, Windisch S, Mormann WH. Full-ceramic CAD/ CAM anterior crowns and copings. Int J Comput Dent 1989; 2:97-111.

5. Borba M, Cesar PF, Griggs JA, Della Bona A. Adaptation of all-ceramic fixed partial dentures. Dent Mater 2011;27(11):1119-26.

6. Coli P, Karlsson S. Fit of a new pressuresintered zirconium dioxide coping. Int J Prosthodont 2004;1 7:59-64.

7. Conrad HJ, Wook-Jin Seong WJ, Pesun IJ. Current ceramic materials and systems with clinical recommendations: A systematic review. J Prosthet Dent 2007; 98:389-404.

8. Contrepois M, Soenen A, Bartala M, Laviole O. Marginal adaptation of ceramic crowns: a systematic review. J Prosthet Dent. 2013;110(6):447-54.e10.

9. Dietschi D, Spreafico R. Adhesive Metal Free Restorations. Current Concepts for the Esthetic Treatment of Posterior Teeth, Quintessence publishing Co.Inc., Chicago, 1997

10. Dittmer MP, Borchers L, Stiesch M, Kohorst P. Stresses and distortions within zirconia-fixed dental prostheses due to the veneering process. Acta Biomater 2009; 5(8):3231-9.

11. Emiroglu S, Evren B, Kulak Ozkan Y. Effect of Cements at Different Temperatures on the Clinical Performance and Marginal Adaptation of Inlay-Onlay Restorations In Vivo. J Prosthodont. 2016;25(4):302-09.

12. Garcia AJ, Santana FB, Szalay ER. Marginal adaptation and microleakage comparison between two zirconia oxide systems. R Odonto Mexicana 2011;15(2):101-6.

13. Gassino G, Monfrin SB, Scanu M, Spina G, Preti G. Marginal adaptation of fixed prosthodontics: A new in vitro 360 degree external examination procedure. Int J Prosthodont 2004; 17:218-23.

14. Gavelis JR, Morency JD, Riley ED, Sozio RB. The effect of various finish line preparations on the marginal seal and occlusal seat of full crown preparations. J Prosthet Dent 1981;45(2):138-145.

15. Gavelis JR, Morency JD, Riley ED, Sozio RB. The effect of various finish line preparations on the marginal seal and occlusal seat of full crown preparations. J Prosthet Dent 2004;138-145. 
16. Gemalmaz D, Ozcan M, Alkumru HN. A clinical evaluation of ceramic inlays bonded with different luting agents. J Adhes Dent. 2001;3(3):273-83.

17. Goldin EB, Boyd NW, Goldstein GR, Hittelman EL, Thompson VP. Marginal fit of leucite-glass pressable ceramic restorations and ceramicpressed-to-metal restorations. J Prosthet Dent 2005; 93:143-7.

18. Gonzalo E, Suarez MJ, Serrano B, Lozano JF. A comparison of the marginal vertical discrepancies of zirconium and metal ceramic posterior fixed dental prostheses before and after cementation. J Prosthet Dent 2009;102: 378-84.

19. Good ML, Mitchell CA, Pintado MR, Douglas WH. Quantification of all-ceramic crown margin surface profile from try-in to 1-week post-cementation. J Dent 2009;37(1):65-75

20. Goodacre CJ, Campagni WV, Aquilino SA. Tooth preparations for complete crowns an art form based on scientific principles. J Prosthet Dent 2001; 85:363-376.

21. Göhring TN, Roos M. Inlay-fixed partial dentures adhesively retained and reinforced by glass fibers: clinical and scanning electron microscopy analysis after five years. Eur J Oral Sci. 2005;113(1):60-69.

22. Groten M, Axmann D, Probster L, Weber H. Determination of the minimum number of marginal gap measurements required for practical in-vitro testing. J Prosthet Dent. 2000;83(1):40-9.

23. Guess PC, Strub JR, Steinhart N, Wolkewitz M, Stappert CF. All-ceramic partial coverage restorations-midterm results of a 5-year prospective clinical splitmouth study. J Dent. 2009;37(8):627-37.

24. Heffernan MJ, Aquilino SA, Diaz-Arnold AM, Haselton DR, Stanford CM, Vargas MA. Relative translucency of six allceramic systems. Part I: core and veneer materials. J Prosthet Dent 2002; 88:10-15.

25. Heintze SD. Clinical relevance of tests on bond strength, microleakage and marginal adaptation. Dent Mater 2013;29(1):59-84.

26. Holmes JR, Bayne SC, Holland GA, Sulik WD. Considerations in measurement of marginal fit. J Prosthet Dent 1989; 25:405-8.

27. Knoernschild KL, Campbell SD. Periodontal tissue responses after insertion of artificial crowns and fixed partial dentures. J Prosthet Dent 2000; 84:492-8.

28. Kunii J, Hotta Y, Tamaki Y, Ozawa A, Kobayashi Y, Fujishima A, Miyazaki T, Fujiwara T. Effect of sintering on the marginal and internal fit of CAD/CAM-fabricated zirconia frameworks. Dent Mater J 2007;26(6):820-6.

29. Laurent M, Scheer P, Dejou J, Laborde G. Clinical evaluation of the marginal fit of cast crowns-validation of the silicone replica method. J Oral Rehabil 2008;35(2):116-22.

30. McCabe JF, Walls AWG. Appplied Dental Materials. $8^{\text {th }}$ ed, Blackwell Science Ltd., Malden, USA, 1998

31. McLean JW, von Fraunhofer JA. The estimation of cement film thickness by an in vivo technique. Br Dent J. 1971;131(3):107-11.

32. Mitchell CA, Pintado MR, Douglas WH. Nondestructive, in vitro quantification of crown margins. J Prosthet Dent 2001;85(6):575-84.
33. Nawafleh NA, Mack F, Evans J, Mackay J, Hatamleh MM. Accuracy and Reliability of Methods to Measure Marginal Adaptation of Crowns and FDPs: A Literature Review. J Prosthodont 2013; 3:97-111.

34. Pera P, Gilodi S, Bassi F, Carossa S. In vitro marginal adaptation of alumina porcelain ceramic crowns. J Prosthet Dent 1994;72(6):585-90.

35. Pilo R, Cardash HS. In vivo retrospective study of cement thickness under crowns. J Prosthet Dent 1998;79(6):621-5.

36. Quante K, Ludwig K, Kern M. Marginal and internal fit of metal-ceramic crowns fabricated with a new laser melting technology. Dent Mater 2008; 24:1311-15.

37. Quintas AF, Oliveira F, Bottino MA. Vertical marginal discrepancy of ceramic copings with different ceramic materials, finish lines, and luting agents: an in vitro evaluation. J Prosthet Dent 2004;92(3):250-7.

38. Rahme HY, Tehini GE, Adip SM, Ardo AS, Rifai KT. In vitro evaluation of the replica technique in the measurement of the fit of procera crowns. J Contemp Dent Pract 2008;9(2):2532.

39. Rosenstiel SF, Martin FL, Fujimoto J. Contemporary Fixed Prosthodontics. $4^{\text {th }}$ ed, Mosby, St. Louis, 2006.

40. Roulet J, Reich T, Blunck U, Noack M. Quantitative margin analysis in the scanning electron microscope. Scanning Microsc. 1989;3(1):147-58; discussion 58-9.

41. Roulet JF, Herder S. Bonded ceramic inlays. Quintessence Publishing Co, Inc., Chicago, 1991

42. Schillinburg HT, Hobo S, Whitsett LD, Jacobi R, Brackett SE. Fundamentals of fixed prosthodontics. $3^{\text {rd }}$ ed, Quintessence Publishing Co. Inc, 1997; 85-103,142-154.

43. Shearer B, Gough MB, Setchell DJ. Influence of marginal configuration and porcelain addition on the fit of In-Ceram crowns. Biomaterials 1996;17(19):18915 .

44. Sulaiman F, Chai J, Jameson LM, Wozniak WT. A comparison of the marginal fit of In-Ceram, IPS Empress, and Procera crowns. Int J Prosthodont 1997;1 0:478-84.

45. Thordrup M, Isıdor F, Hörsned-Bindslev P. Comparison of marginal fit and microleakage of ceramic and composite inlays:an in vitro study. J Dent 1994; 22:147-53.

46. Tsitrou EA, Northeast SE, van Noort R. Evaluation of the marginal fit of three margin designs of resin composite crowns using CAD/CAM. J Dent, 2007;35(1):68-73

47. Van Dijken J, Hörstedt P. Marginal breakdown of fired ceramic inlays cemented with glass polyalkenoate (ionomer) cement or resin composite. J Dent. 1994;22(5):265-72.

48. Wolfart S, Wegner SM, Halabi A, Kern M. Clinical Evaluation of Marginal Fit of a New Experimental All-Ceramic System Before and After Cementation. Int J Prosthodont 2003; 16:587-92.

49. Yeo IS, Yang JH, Lee JB. In vitro marginal fit of three allceramic crown systems. J Prosthet Dent 2003;90(5):459-64.

50. Yildiz C, Vanlioğlu BA, Evren B, Uludamar A, Ozkan YK. (2013). Marginalinternal adaptation and fracture resistance of CAD/CAM crown restorations. Dent Mater J 2013;32(1):42-7. 